\title{
Projeções de atrasos e hesitaçóes: perspectivas em torno de um projeto de aceleração em uma escola pública do Rio de Janeiro $(\mathrm{RJ})$
}

MARIO PEREIRA BORBA

UNIVERSIDADE FEDERAL DO RIO DE JANEIRO (UFRJ), RIO DE JANEIRO/RJ, BRASIL HTTPS://ORCID.ORG/OOOO-0002-I289-7252

para quem quer se soltar invento o cais Milton Nascimento

\section{Introdução}

Neste artigo, abordo e discuto a experiência de um projeto de aceleração ou adaptação idade-série, o CAIS - Classe de Adaptação Idade-Série. Acompanhei o desenvolvimento desse projeto em uma escola pública federal desde seus primeiros entendimentos: das discussões em torno de sua concepção e convites para participação, em reuniões de planejamento, ao longo do segundo semestre do ano letivo de 2017, até o desenrolar das aulas no semestre seguinte, já em 2018.

A escola na qual realizei esse trabalho de campo situa-se na zona norte do município do Rio de Janeiro. Tal instituição é de grande importância para o bairro no qual está localizada, próxima de duas favelas e de uma estação de acesso à malha de trens que cruza a imensidão metropolitana. Nela, circulavam aproximadamente cento e cinquenta professores, em torno de mil e duzentos alunos e quarenta funcionários, de todos os cantos da cidade.

A partir de um trabalho de campo diário, que durou pouco mais de um ano, produzi uma etnografia enquanto tese de doutorado; "essa tese aborda mobilizações de atenção e cuidado em torno da concepção de problemas de estudantes com comportamentos não conformes ou perturbadores" (Borba 2019:7). Nela, discuto esses problemas e as correlatas expectativas envolvidas neles, como na 
mobilização da atenção enquanto uma das grandes empreitadas escolares, concebida de várias formas nesse cotidiano, entre relações de força e de cuidado.

Neste artigo, contemplo uma situação específica dentre o que observei em campo, mas que se comunica com questões mais amplas tanto da minha tese quanto da escolaridade no Brasil, talvez o mais ordinário dentre os problemas que observei: a multirrepetência no segundo ciclo do Ensino Fundamental (do sexto ao nono ano), sobre o qual incidiu o referido projeto.

Durante a imersão em campo, no que tange a esse projeto, tive a oportunidade de acompanhar reuniões (seis no total das mais formais, com duração aproximada de duas horas), situações e discussões cotidianas, bem como de realizar algumas entrevistas não diretivas, gravadas, para uso pessoal (doze no total, das quais três foram em duplas, e as demais, individuais). A fim de preservar o anonimato que combinei com meus interlocutores, situo as questões e situações provenientes dessa experiência em torno do fundamental para discuti-la, sem enveredar por especificidades de personagens e relações, referindo-me, por exemplo, genericamente a "um professor" ou a "um aluno" diante de alguma situação ou fala.

O CAIS foi desenvolvido para acolher alunos com mais de dois anos de defasagem no segundo segmento do Ensino Fundamental. Ou seja, alunos que repetiram algumas vezes e que estavam entre o sexto e o nono ano para, em um ano letivo, avançarem dois. É evidente que essa multirrepetência era uma questão incômoda para todos os envolvidos, disparadora de preocupações em diferentes níveis, de desgaste cotidiano de alunos e professores no âmbito de gestão, bem como da inquietação e urgência que deram origem ao projeto.

$\mathrm{Na}$ esfera institucional, essa urgência estava relacionada a certo "inchaço" das turmas do segundo ciclo do Fundamental, cujo trabalho pedagógico era complicado por si só - considerando constituir-se em um momento e lugar específicos (inclusive no aspecto espacial, no edifício) da escola, que faz a conexão entre os primeiros anos da escolaridade e o Ensino Médio. Diante disso, a instituição precisava, a cada ano letivo, distribuir e acomodar um acúmulo de repetentes.

O fato de um número suficiente de participantes potenciais para a formação dessas duas turmas exclusivas de multirrepetentes ter sido rapidamente alcançado atesta a gravidade em torno dessa questão. A pronta adesão ao projeto - da parte da escola, de professores, alunos e seus responsáveis - evidencia a sensação de urgência que o circundava. Nas discussões sobre o projeto, registravam-se, informalmente, alguns panoramas de ordem socioeconômica impactantes, como o deslocamento diário de certos jovens que moravam em bairros muito distantes da escola, além de situações de vulnerabilidade envolvidas nas condições de residência ou na relação com as famílias.

Esse foi um projeto que tratou de algumas experiências-limite da escola, acentuando frustrações, estranhamentos e fracassos. Não era comumente referido como um projeto de aceleração, embora a rigor o fosse. Uma vez formulado e constituídas as turmas, manteve-se sendo denominado pela sugestiva sigla CAIS que, para além de eventuais trocadilhos ou atos falhos nas suas menções cotidianas, como "caos", insinuava alguns sentidos. Para mim, sempre ressoou o sentido de um lugar de embarque e desembarque. 
A iniciativa foi toda acompanhada de profundas discussões sobre seu sentido. Desenvolvo, em outro artigo, uma reflexão mais próxima do horizonte prático de questões pedagógicas, em torno, por exemplo, da sistematização das aulas diante da incumbência ou liberdade para desenvolver diferentes formas de ministrá-las (Borba, Azize 2020). Aqui, procuro apontar para uma abordagem mais ampla desse processo, nas formas como se constrói a existência de um personagem como o repetente, por exemplo, e as problematizações que ele coloca para a escola.

No rastro de atrasos ou acelerações, penso em uma concepção de tempo investida e operada pela escola. Como já refletiu Franch (2008; 2016; 2018:101), o tempo

está no cerne de um vasto conjunto de significados que vem à tona quando o assunto são os jovens. Transição, passagem, geração, futuro, disciplina, são algumas das palavras mobilizadas ao pensarmos nessa fase da vida, e que têm a ver com questões como o fluxo do tempo e suas descontinuidades.

Considerando certas normatividades escolares sobre fluxo do tempo e suas descontinuidades, desenha-se um forte paralelo do projeto de adaptação idade-série que abordo nesse artigo com a Educação de Jovens e Adultos (EJA). Como observa Lima (2018: 108):

a própria Educação de Jovens e Adultos, modalidade de ensino e política pública educacional, presente nos principais documentos normativos da Educação brasileira, é pensada fundamentalmente como prática que visa, sobretudo, com a adesão do Brasil ao um [sic] modelo socioeconômico desenvolvimentista "corrigir", "recuperar", "acertar" o tempo de escolarização dos sujeitos a partir do binômio, ano-idade.

Esse paralelo nos fala, dentre outras coisas, de um silencioso processo de exclusão que o sistema educacional põe em funcionamento, que é notável em estudos sobre a EJA (Santos 2003; Lima 2018; Fonseca 2001). Esse tipo de projeto incide sobre uma heterogeneidade dos percursos, de forma a "reparar" "equalizar" ou "ajustar" diferentes tempos que são qualificados como problemáticos na escolarização.

Ponderar sobre o uso do tempo diante dessas noções (ou o "uso correto do tempo") enquanto uma construção social; conceber e estranhar a reincidência de personagens e qualificações como repetente em termos cotidianos; fazer ressoar o silêncio de uma dissidência. Entendo que, nesse tipo de ponderação, está uma contribuição potencial da abordagem etnográfica e antropológica do cotidiano escolar, já que pensar a alteridade e refletir sobre o contato com o outro e com as diferenças é característico do pensamento antropológico, como já destacou Gusmão (1997).

O problema da repetência ou do fracasso escolar são tradicionais nos debates e pesquisas sobre educação no Brasil (Patto 2015, Bahia 2009 e Bossa 2008 são alguns exemplos; para um panorama mais completo, ver Angelucci et al. 2004), os quais não percorrerei no espaço deste artigo. Minha intenção aqui é explorar questões que atravessaram o cotidiano escolar durante a concepção e o desenvolvimento do projeto em foco, algumas das quais explicitamente formuladas. Comecemos por uma delas, talvez a principal. 
Quando os problemas na relação da escola com esses jovens repetentes se fazem presentes com mais força, há (quase sempre) uma questão disparadora: e se a culpa for da escola? O que cabe então repensar? A diretora, no início da primeira reunião entre professores relacionada ao projeto, disse: “Acredito que todo mundo aqui concorda que não é culpa deles". Ninguém ali discordou.

Essa colocação e o tom das primeiras reuniões reforçaram uma impressão de relativo alinhamento com premissas do pensamento escolanovista ${ }^{1}$ entre os docentes envolvidos, de que a estrutura e o funcionamento institucionais, bem como os métodos de ensino, seriam os principais responsáveis pelas dificuldades de aprendizado, sendo preciso adaptá-los às necessidades e possibilidades dos alunos. Principalmente nos momentos em que se discutia o projeto de forma mais ampla, sem enveredar nos históricos de cada jovem elencado para ele, acentuava-se um processo desenrolado ao longo desses anos de escolaridade, em detrimento de uma condição negativa.

Nisso, aparecia o entendimento de que a escola, por diferentes motivos, não havia conquistado esses jovens que, ainda assim, não a abandonavam, fossem quais fossem os motivos. Vale mencionar que as três razões para permanência que mais apareciam eram: a pressão familiar, um enunciado recorrente sobre a importância da escola para a vida e os amigos que tinham ali.

Uma consideração consensualmente comentada pelos professores, que abordaremos adiante, era que esse descompasso de idade-série contribuía para afastá-los ainda mais da escola, deslocados nas turmas onde eram realocados (com colegas mais infantis), além de uma eventual liderança ou influência negativa que alguns deles exerciam em suas turmas, atrapalhando a dinâmica das aulas. Dessa maneira, a expectativa de recuperar um "tempo perdido" e reaproximá-los das turmas de origem (antes das repetências) seria (e foi) um estímulo para a adesão ao projeto.

Uma vez elencados os alunos "aptos" ao CAIS, sob esse critério de defasagem, eles e suas famílias foram consultados sobre o interesse em participar do projeto, em convocações e reuniões separadas com a direção da escola. A sensação nessas conversas anteriores às convocações era de certa urgência, de certa dívida com eles, da qual decorreu um renovado entusiasmo da maior parte dos envolvidos.

Alguns dos elencados para essas convocações não apareciam na escola fazia já algum tempo. Diante de um nome lembrado em uma reunião, por exemplo, do qual não se sabia o paradeiro, uma professora comentou ironicamente e em tom franco (como quem diz, "convenhamos, indiretamente”): “A gente jubilou o Felipe, né?!". Ou seja, no somatório de reprovações, repreensões, advertências e suspensões, a escola teria operado esse afastamento, remetendo-se nesse movimento à já abolida prática do jubilamento.

Desenha-se certa sintonia na percepção da situação desses alunos, que considera o jubilamento - não só como prática oficial, mas como movimento de afastar um aluno da escola - como algo constrangedor e negativo. No rastro dessa menção, lembremos que o jubilamento de alguma forma "resolvia" questões, expulsando os estudantes multirrepetentes da escola, individualizando o problema. É o

1 Em referência ao movimento de renovação do ensino desenvolvido no Ocidente a partir do final do século XIX, chamado Escola Nova e popularizado no Brasil no começo do século XX, principalmente por meio do "Manifesto dos Pioneiros", em 1932 (Cury 1988 ; Patto 2015). 
fim dessa prática institucional que permite considerar de forma mais ampla e contínua essas trajetórias discentes dentro da escola.

\section{Agrupamentos e trocas}

Foram assim reunidos dois grupos de professores, relacionados às duas turmas criadas nesse projeto, uma equivalente ao sexto e sétimo e outra ao oitavo e ao nono ano do Ensino Fundamental. Ambos os agrupamentos, de alunos e professores, renderam trocas, a começar pelas reuniões. Ou melhor, como já sugeriu Goldman (2016), não existem grupos que trocam, existem trocas que grupam: todo agrupamento é uma nova perspectiva. Aquela questão levantada pela diretora na reunião inicial, acerca da concordância de que a culpa pela repetência não era do alunado e a observação da professora sobre o problema moral do jubilamento dão uma sugestão aproximada de perspectiva da parte dos docentes.

Sobre os alunos, cabe observar que as duas turmas, montadas por um critério de maior defasagem na trajetória escolar, acabaram majoritariamente compostas por alunos negros (algo como oito negros para cada branco) e de classes populares. Não cabe aqui apurar a minúcia de critérios, proporções e definições nessas classificações aproximadas, mas são marcadores que não podem ser desprezados na consideração de um projeto como esse. Vale lembrar que atravessamentos entre marcadores sociais e fracasso ou sucesso escolar são temas tradicionais no pensamento sobre educação no Brasil (Zago 2000; Carvalho 2003; Patto 2015; Silva 2011).

Para além do que ficava evidente nos agrupamentos em si, o projeto suscitava, de uma forma geral, tentativas de compreensão dos modos como esses jovens produziram seus percursos e suas presenças dentro da escola. E, talvez principalmente, como a instituição reagia a eles, como qualificava esses trajetos e seus ritmos peculiares, nos modelos de estratificação das performances individuais (comumente referidos como "meritocracia") que a escola produz e reproduz.

Esse processo, tanto de modo mais amplo, como particularizado em cada história, incluiu pensar sobre os sentidos relacionados a estar ou não na escola para cada um, expressos nesse projeto em uma expectativa de "alguma outra coisa" a ser produzida na relação com o ambiente de ensino, seja ela qual for ou nas expectativas para fora dele. Essas projeções revolviam a frustração ou alegria de cada passagem de ano, com reprovação ou aprovação.

Logo no início do trabalho com as turmas do CAIS, uma professora, ao discorrer sobre a dificuldade em administrar essas aulas da segunda turma (que compreendia oitavo e nono anos), comentava comigo especialmente sobre a complexidade de trabalhar no projeto:

É muito difícil você atingir todo mundo. Às vezes você chega, dá aquela aula com exercícios; tem aquela meia dúzia que está interessada em seguir aquele caminho e tem aquele povo que não quer. Eu acho assim... que não devia ter aluno de sétimo ano. Essa primeira turma tinha que ser só alunos completamente... que eram do oitavo e do nono ano e que estão atrasados, não aquele aluno que fez o sexto ano mil vezes, o sétimo ano mil vezes, aí passou do sétimo e foi jogado ali. Para esse primeiro momento, para essa primeira experiência [...] em que estamos construindo uma cabeça para trabalhar com essas pessoas, ter tantas realidades diferentes... (grifo meu). 
Nesse momento, eu assinalo a ela que esse "outro aluno" (duas vezes “outro”, poderíamos pensar) teria mais defasagem e, a princípio, mais necessidade do projeto, conforme os critérios que orientaram a elaboração dele. A docente então replicou:

\begin{abstract}
Sim, mas seria mais homogêneo. Esse aluno do sétimo ano responde melhor porque veio de uma aprovação. Aí eles veem isso como uma solução para a vida deles, porque aí ele vai se readequar à idade. Agora aqueles outros estão muito atrasados mesmo. [...] São realidades muito, muito diferentes, tudo na mesma turma. Então, se não tivesse esse povo [recentemente aprovado, recém-vindo] do sétimo ano, essa turma seria muito mais sufocante, mas você enxergaria de outra forma. Aí você fala assim, ah pô, ninguém vai querer fazer o Ensino Médio aqui porque está todo mundo mais atrasado, eles querem mais é terminar o Fundamental para fazer um ENCCEJA ${ }^{2}$ da vida e garantir o diploma, ninguém tem expectativa de fazer uma faculdade da vida, mas esse povo que veio aprovado do sétimo, eles têm essa expectativa, eles têm esse interesse de continuar, de fazer o Ensino Médio, de fazer uma faculdade, de progredir.
\end{abstract}

Esse depoimento é especialmente marcante no que procuro enfatizar e discutir em termos de agrupamentos e trocas, que aqui são postos em diálogo com uma perspectiva sobre os engajamentos produzidos e possíveis. Outro ponto representativo a ser recuperado é a incidência da escolaridade em uma concepção de temporalidade que pesa sobre esses jovens, em termos de atrasos, por exemplo, que aqui insinua construir uma realidade diferente. Diante de diferentes expressões de defasagem, situam-se possibilidades de produção e engajamento em sala de aula, das quais decorrem outras clivagens que, espontaneamente, vão se desenhando no cotidiano, nas formas de perceber e qualificar essas presenças na escola.

Aqui se esboça uma possível qualificação de um desses agrupamentos no CAIS, "aquele povo que não quer", dentre aqueles que não "topavam" a instituição de ensino da forma como essa vinha se apresentando para eles. De alguma maneira, não só pelo vislumbre de imaginação de um "povo" (o que não quer), algumas dessas narrativas em torno do fracasso e da frustração remetem-me ao "flagrante delito das fabulações”, tal como sugerido por Deleuze (2010: 161) em seu texto seminal sobre a "sociedade de controle":

O que é preciso é pegar alguém que esteja "fabulando", em "flagrante delito de fabular". Então se forma, a dois ou em vários, um discurso de minoria. Reencontramos aqui a função da fabulação bergsoniana... Pegar as pessoas em flagrante delito de fabular é captar o movimento de constituição de um povo. Os povos não preexistem. De certa maneira, o povo é o que falta, como dizia Paul Klee. Será que existia um povo palestino? Israel diz que não. Sem dúvida existia um, mas isso não é o essencial. Pois, a partir do momento em que os palestinos são expulsos de seu território, na medida em que resistem, eles entram num processo de constituição de um povo. Isto corresponde exatamente ao que Perrault chama de flagrante delito de fabular. [...] Não existe verdade que não "falseie" ideias preestabelecidas. Dizer "a verdade é uma criação" implica que a produção da

2 Sigla de Exame Nacional para Certificação de Competências de Jovens e Adultos, que pode ser realizado, de forma voluntária e gratuita, para pleitear certificação nos níveis de conclusão do Ensino Fundamental (maiores de 15 anos) e do Médio (maiores de 18 anos). 
verdade passa por uma série de operações que consistem em trabalhar uma matéria, uma série de falsificações no sentido literal.

Deleuze (2010) afirmava que o essencial sobre esse "povo que falta" não é saber se existe ou não. O autor propõe pensar esse processo de constituição de um povo (o palestino) afinado com o referido "flagrante delito" de fabular, na medida em que esse coletivo resiste, em que é expulso de um lugar. Uma troca, um agrupamento. Esse processo "falseia ideias pré-estabelecidas": pensemos aqui sobre os nivelamentos e adaptações entre idade e série em um "ensino regular". Esse "povo" gera então, acompanhando essa aproximação, uma bifurcação, uma série complicada, um ritmo incomum, um novo agrupamento.

Assim como no exemplo mencionado por Deleuze (2010), dos palestinos expulsos de um território, esses jovens do CAIS foram de alguma forma expulsos de um lugar - se não da escola (visto que os jubilamentos já estão em um passado remoto e constrangedor), da dinâmica de uma escolaridade tida por regular sobre a qual oferecem alguns falseamentos. Em torno do projeto eram discutidas constantemente algumas práticas que poderiam ser pensadas nesse sentido, seja em aprovações forçadas anteriores por conselhos de classe (sem real merecimento dos alunos) ou nos chamados desenrolos em torno de demandas cotidianas da escola (expedientes de malandragem e persuasão, assim como histórias inventadas).

Entendo que essa dinâmica de qualificaçôes em diferentes níveis que aparece na fala dessa professora é muito característica da rotina escolar, ganhando especial evidência em conselhos de classe, com os "mais e os menos interessados", os "mais comportados", "os mais bagunceiros", e assim por diante. Perante essas mobilizações e referências, é recorrente a ideia de um progresso a partir da educação formal, como algo para "subir na vida", avançar, progredir; de onde certa "aceleração" (ou possibilidade de aceleração) soa como positiva, talvez como uma outra face do "A" de "adaptação" na sigla do projeto.

Os estudantes contemplados pelo CAIS eram genericamente percebidos como em uma espécie de deriva, na medida em que não se distanciavam completamente da escola, já que não a abandonaram oficialmente, mas também não se engajavam no que era demandado no ensino regular, colecionando reprovações. Daí a sugestiva palavra formada pela sigla desse projeto, o "cais", como esse ponto de embarque ou desembarque, ou, como também sugere o dicionário, um reforço construído nas margens de um canal, destinado a conter e direcionar os fluxos, em uma dinâmica entre movimento e repetição.

O depoimento da professora toca também nos fluxos de ânimo ou desânimo a partir da situação específica de cada jovem, evidenciada na disposição em sala de aula. O passado recente é apontado como explicação do porquê o aluno aprovado no sétimo ano responde melhor: veio de um êxito recente e, nesse embalo, veria o projeto como "uma solução para a vida".

As ideias de aceleração e solução ganham complexidade nesses agrupamentos, em diálogo com a percepção do engajamento no que é proposto na escola. $\mathrm{O}$ estudante que vem aprovado do sétimo tenderia, na leitura da docente, a uma continuidade da escolaridade que se posiciona como regular. $\mathrm{Ou}$ seja, a aceleração promovida pelo projeto corrigiria o atraso, e ele poderia então retomar esse curso, no que é positivado enquanto um possível trampolim para uma faculdade (para "progredir"). 
O aluno que vem desmotivado da reprovação recente, por sua vez, (lembrando que todos eles possuíam um histórico de reprovações) é envolvido na perspectiva de uma espécie de pendência que pesa sobre o estudante, na qual o CAIS (e eventualmente o ENCCEJA, quando tiverem idade) se apresenta também como (re)solução. Não quero aqui entrar no mérito dessas projeções, mas enfatizar o quanto a experiência de repetir de ano cria ou recria uma posição de certa exterioridade no cotidiano escolar, mesmo quando se está em um projeto onde ela é experiência comum.

\section{Escola e fracassos reproduzidos}

Julgo importante uma pequena pausa, para recuperar, ainda que abreviadamente, uma problematização da construção e da atualidade da noção de juventude e da própria instituição escolar enquanto tecnologia pedagógica. Já evidenciamos a participação da escola na organização e imposição de uma ideia de tempo, estritamente relacionada à percepção da juventude. É evidente que, em torno dessas acepções, insinuam-se regularidades, ritmos e descontinuidades.

Diante de um projeto como o que abordamos aqui, é instigante, portanto, repassar essas contribuições, que investem contra a naturalização de modelos ocidentais comuns de escola (de pontos de vista cultural, histórico e contingente); de juventude (pensemos também no controverso e relativamente atual conceito de adolescência) e dos arranjos que pairam como ideais em torno de ambos ${ }^{3}$. A suspensão dessas preconcepções é um modo de evidenciar formas como a escola e a juventude são (re)produzidas.

Bourdieu (1983) contextualiza a emergência da adolescência, por exemplo, enquanto um estatuto temporário, uma existência separada na qual se estaria coletivamente fora do jogo, como um fato social diretamente relacionado à transformação do sistema escolar. A escola, ou melhor, a saída da escola, passa a ser valorizada e concebida como uma entrada no mundo adulto, como também observaram e discutiram Guedes (1997) e Willis (1991). Então, um dos efeitos fundamentais decorrentes da contribuição da escola nesse entreato, destacado nas reflexões de Bourdieu (2003), é a manipulação das aspirações.

Cabe então questionar qual o papel das instituições de ensino nessas aspirações; no complicado jogo travado entre interioridades e a concentração (no que é colocado pela escola) ou entre exterioridades e descentramentos (com relação a ela enquanto espaço de aprendizagem e preparação). Em outras palavras, como a escola se situa na produção de tipos de investimentos sobre as formas de estar no mundo, que configuram a complexa elaboração da saída dela ou preparação para a vida adulta.

O CAIS incita justamente a pensar nessas passagens, sobre as formas como a escola lida com algumas situações que parecem distanciadas do curso compreendido como regular da aprendizagem, refletindo especialmente sobre as preparações para a saída da escola. Diante disso, é impossível não lembrar de outro clássico, a etnografia de Willis (1991) com "jovens ressentidos" e sua exploração analítica do que ele chama de "cultura contra-escolar". Esses jovens habitavam uma margem a partir da qual esse autor levantou algumas questões interessantes para as concepções de uma educação pública.

3 Sobre a produção e reiteração das noções de adolescência e juventude como moeda corrente para explicar e justificar fenômenos sociais, bem como acerca do lugar da escola na produção dessas noções, cabe recordar as contribuições de Ariès (1978) e Fischer (1996). 
Ainda que datada por diversos aspectos - passo ao largo das correlações entre "chão de fábrica" e "classe", "cultura" e "ideologia" -, a contribuição mais etnográfica desse livro explora uma negação difícil de ser compreendida e enfrentada: por que esses jovens não aceitavam a escola?

Willis (1991) suscita questões sobre o sentido do que esses jovens estavam fazendo; sobre como eles percebiam a passagem pela escola; como processavam o que era convocado e como entendiam o que era cultuado nesse universo. Considero que um ponto interessante dessa etnografia é justamente enveredar nessa "negatividade", no que ele vai chamar de "cultura contra-escolar". O autor desenvolve as formas irônicas pelas quais esses jovens habitavam a escola, sem para isso centrar (demais) o olhar no que estava colocado por essa instituição e, assim, simplificar a posição deles, relativamente, como uma simples oposição, traçando conexões mais amplas, externas, como com o "chão de fábrica". Considero que a riqueza desse material está, portanto, nas formas como esses “jovens ressentidos" davam sentido para o que viviam, para a escola, para o trabalho, para o futuro e todo o tipo de questão que atravessava essa presença institucional, com o intuito de, a partir disso, repensar essa entidade aparentemente negada e desvalorizada por eles.

Cabe pensar, sob tal inspiração, essas relações produzidas entre a escola e esses jovens do CAIS para além das negatividades envolvidas nas reprovações. Com Foucault (2012), entendo que são, evidentemente, relações de poder, mas positivas, que produzem disposições e sujeitos. Trata-se de um poder que opera na variação de tecnologias e táticas, bem como opera a partir de investimentos e estímulos.

Foucault (2012) nos induz a perceber as resistências intrínsecas em meio a essas tramas. Pensar escoras, guaritas, espaços vazios ou distâncias produzidas nessas relações, que podem servir para fixar interdições, para normatizações, para articular diferenças. Sob a mesma inspiração, penso que iniciativas como o projeto em tela não servem, necessária e univocamente, a alguma estratégia, não marcham em uma única direção em progressões lineares, mas são polivalentes e, eventualmente, descontínuas. Da mesma forma, os discursos desses jovens não devem ser percebidos como estando "de um outro lado" das relações de poder que configuram a escola, como um contraposto ou simples efeito de disposições, mas justamente como partes que constituem essas correlações de força, essas relações de poder, isto é, positividades.

Ambos os autores nos propõem, portanto, uma sensibilidade que contraria os atalhos pelos quais o problema da multirrepetência pode ser pensado. Essas relações de poder, tal como se configuram na escola, produzem disposições e sujeitos, sendo essencialmente positivas e produtivas. Desse modo, não cabe subsumi-las na consideração da oposição ou da simples negação do que é proposto na escolaridade regular.

Nessa esteira, para conceber o fracasso escolar, cabe mencionar o clássico e seminal estudo de Patto (2015). Nessa pesquisa, desenvolvida na década de 1980 e publicada pela primeira vez nos anos 1990, a autora sintetizou algumas máximas que orientaram o pensamento sobre educação no Brasil, especialmente em torno da questão antes referida. Ainda que o trabalho seja relativamente antigo, há pontos que sugerem proximidades com algumas perspectivas sobre cada história envolvida no CAIS.

Enfatizo duas máximas destacadas pela autora que, colocando em primeiro plano marcadores de classe, tratam de inadaptações envolvidas no fracasso estudantil: "as dificuldades de aprendizagem 
escolar da criança pobre decorrem de suas condições de vida"; "a escola pública é uma escola adequada às crianças de classe média e o professor tende a agir, em sala de aula, tendo em mente um aluno ideal” (Patto 2015:144). Disso decorre a ideia de uma carência cultural, uma diferença negativada; uma ideia de que a escola, em seu funcionamento normal, seria palco de uma espécie de inadequação desencorajadora e que, por isso, não atenderia a alguns desses jovens.

A autora, junto de uma equipe de pesquisadores, realizou trabalho de campo em uma escola de um bairro popular paulista, onde entrevistou professores, membros da direção, alunos e seus responsáveis. Sobre essa experiência, Patto (2015:223) reflete:

Desde o início dispúnhamos de uma pista de que a ambiguidade poderia ser uma característica da visão dos educadores sobre a questão da reprovação; mais do que isto, que a tendência mais forte seria a responsabilização do aluno. Na primeira vez em que conversamos com Maria José [de cargo equivalente a uma diretoria pedagógica dessa escola], ela se refere às crianças reprovadas através de uma intrigante estrutura linguística: fala repetidas vezes de "crianças que se reprovaram". Embora esta seja uma forma sintaticamente correta de dizer na língua portuguesa "crianças que foram reprovadas" por um sujeito indefinido, ela é pouco usual. Quando a ouvimos, entendemos "crianças que reprovaram a si mesmas", uma versão sobre a repetência compatível com a ideia de que se oferece a esses alunos a oportunidade de aprender, que eles aproveitarão ou não em função de suas características individuais e familiares. Essa incoerência, contudo, está muito mais presente no discurso do que na ação que essas educadoras desenvolvem na escola: nas práticas e processos de que participam, as dificuldades de aprendizagem são implícita ou explicitamente atribuídas a algum distúrbio localizado na criança ou na família, tanto que as medidas mais comumente tomadas consistem em convocar o responsável para "chamá-los às falas", ou encaminhar alunos a serviços de atendimento médico.

Aparecem assim diferentes modalidades de juízos escolares que, ao longo do trabalho de Patto (2015), parecem realizar suas próprias profecias, sendo a principal a identificação de jovens com problemas, que seriam "repetentes" ou prováveis repetentes. Por mais que os professores e direção entrevistados durante essa pesquisa reconhecessem dificuldades estruturais e internas, na escola, essas modalidades de juízos parecem desonerar os envolvidos de buscar fatores endógenos condicionantes dessas situações na prática. Fica evidente, portanto, a força e a perenidade de algumas questões em torno do fracasso escolar, como aquela que apontávamos de saída, lançada na primeira reunião sobre o CAIS. Ressoa em torno disso certas projeções de culpa e de dívidas, relacionadas à compreensão do projeto enquanto um acerto de contas, uma providência. Cabe debruçarmo-nos um pouco sobre essas projeções.

\section{Percepções e dívidas}

Sobre os discursos produzidos nos contatos iniciais desses alunos do projeto com seus professores, desde o convite para participar até as primeiras aulas, muitos expressaram de diferentes formas seu desestímulo com a escola, em uma espécie de círculo vicioso entre indisciplina, distância e indiferença, 
que se retroalimentam em suas demandas escolares. Sobre a presença diária na sala de aula, um dos pontos marcantes na expressão desse desgaste e desestímulo na escolaridade regular era a diferença etária com os colegas de turma, que marcava distâncias. Essa diferença fazia com que, por exemplo, eles fossem lembrados e, eventualmente, referidos em sala de aula pelos professores como os repetentes.

Um dos estudantes do CAIS relatou o desconforto por ser continuamente referido por alguns professores, durante sua carreira no ensino regular, como repetente. Relatou sentir uma expectativa da parte dos docentes para que ele não se aproximasse demais dos outros alunos da sua turma no ensino regular. Outro discente do projeto lembrou de uma cena constrangedora em sala de aula que envolveu um menino, mais novo, com o qual conversava durante uma explicação. O professor interrompeu a aula para chamar a atenção daquele jovem (e não dele), dizendo: "Por que você está aí sentado conversando com ele, quer ficar como ele? Repetente".

Figurar como um exemplo negativo em sala de aula, mesmo com toda indiferença que aparentavam com relação à escola, parecia algo muito sentido por alguns. Eles expressaram também um desconforto íntimo com parte do uniforme, um emblema que estampa no peito o ano em que se encontram no percurso escolar. Afirmou um dos alunos: "Aí... barba na cara e isso [o adereço que identifica o ano, no caso o sexto], galera vê no ônibus, é foda”. Motivo pelo qual alguns andavam com o uniforme incompleto, removendo esse adereço que aparecia como a marca de uma pertença ou de um atraso.

Essas desconcertantes situações sugerem a multiplicidade das formas de reconhecimento das presenças desses estudantes dentro da escola. Fica evidente que, de diferentes formas, o projeto em foco mexe com isso, quando, por exemplo, reagrupa alunos reconhecidos por uma inadequação idade-série. Diante dele, diante também das expectativas e dos estigmas envolvidos, percebo a pista de uma relativa dívida enquanto um aspecto fundamental na percepção dessas presenças na escola.

Já insinuei aqui que o CAIS suscitava elaborações e discussões sobre dívidas da escola perante esses alunos multirrepetentes. Os exemplos que mobilizei agora insinuam também algumas percepções de dívidas deles próprios: diante de seus projetos e perspectivas de trabalho, assim como do acúmulo progressivo dos conteúdos programáticos, devem conseguir se defender e dizer algo mais sobre si; sobre o que pretendem com a escola; eventualmente, sobre o lugar de onde se veem ou para onde pretendem ir; sobre a atualidade que se apresenta para eles; devem responder de outras formas à escola; devem ser mais. A instituição de ensino aparece como um campo de enunciação: a partir de sua presença ali, esses jovens devem mostrar o que são.

Às vezes essa presença era lembrada como apenas corporal: estão "somente de corpo presente na escola”, tal como seguidamente alguns professores observavam. Às vezes, esse corpo parece deslocado e incômodo, como na sentida discrepância entre os adereços barba e uniforme; às vezes, está completamente absorvido em dinâmicas paralelas à programação escolar, na zoeira, que envolve bagunça, flerte, jogo. Muitas vezes, essas presenças são justamente lembradas nessas diferentes ocupações e desenvolturas. Percebo, então, que essas presenças, nessas lembranças, expectativas e abordagens, conjugam dívidas. E que é diante dessas dívidas que essas trajetórias são investidas, aceleradas.

No cotidiano de conversas em torno do CAIS, era comum aparecerem, portanto, questionamentos sobre a importância da educação e da escola para cada um. Os próprios estudantes, ainda que 
em uma situação entendida (por eles e pela escola) como crítica nessa relação, diante dessas questões tão presentes em suas trajetórias ali, reiteravam constantemente algumas máximas a respeito da escola como um percurso necessário, uma caminhada "para ser alguém na vida". Esta última, tantas vezes repetida, já dá o tom do que pode significar o fracasso escolar na vida de um jovem em termos de processos de subjetivação.

\section{Enfrentamentos e oposições}

Diferentes episódios e tipos de enfrentamento davam a tônica de grande parte das narrativas sobre o cotidiano do CAIS. Enfrentamentos entre os próprios estudantes ou entre eles e os professores. A capacidade de desestabilização de uma sala de aula era constantemente lembrada nas observações sobre muitos desses jovens agrupados nas duas turmas do projeto. Alguns docentes observavam que apenas um ou dois desses estudantes já conseguiriam (e conseguiam) desestabilizar uma sala de aula inteira.

O depoimento de um professor sobre o perfil e a formação da turma ajuda a pensar esses enfrentamentos, em termos das proposições e ordenamentos na escola. Ele assinalou que os alunos do CAIS eram justamente os mais populares em suas turmas de origem: "Então, eles ocupavam o lugar, praticamente sozinhos, daqueles do contrapoder, da dissidência absoluta. O poder deles vinha justamente da oposição constituída à figura de autoridade que era o professor, que é a escola”.

Nesse depoimento, o docente evidencia essa posição de "dissidência absoluta", no que tange a relações de poder que constituem o cotidiano da sala de aula, aproximando a ocupação desse lugar de certa popularidade entre os alunos. Já introduzi uma perspectiva relacional sobre o poder, que aqui ganha evidência. Podemos pensar esse enfrentamento à figura de autoridade, sugerido nessa fala em termos de poder, pensando-o enquanto produtor de sujeitos e condutas, tal como sugeri com base no pensamento de Foucault (2012). Temos, portanto, esse embate como produtor de certa disposição nos agrupamentos escolares.

O professor prosseguia falando da reunião desses alunos operada pelo CAIS: "Quando são todos reunidos, a disputa de autoridade começa entre eles, porque eram todos líderes. E ali não tem uma liderança”. Aqui, aparece uma consequência da interferência do CAIS nesses enfrentamentos, que constituem certa regularidade (ainda que combatida) nos ordenamentos escolares, já que a expectativa é que as coisas não seriam, de qualquer forma, iguais nesse sentido no âmbito do projeto. Uma face disso reside no afastamento das turmas regulares desses alunos que concentrariam o que esse docente concebe como o lugar do contrapoder, da dissidência absoluta; outra é a constituição das turmas do CAIS concentrando tal contrapoder. Esse professor apontava que, para além de um "mais do mesmo" em termos de oposição entre esses discentes e professores, a reunião dada pelo projeto teria servido para intensificar disputas e conflitos entre eles mesmos.

Essa observação do docente dá a pista de uma outra dimensão da construção das relações desses jovens com a escola. Se, sob o ponto de vista institucional, expresso no rendimento escolar, nas defasagens e na inadequação aos regimes de comportamento e atenção, são estudantes vistos de alguma forma como outsiders, na esfera das relações cotidianas, da sociabilidade entre alunos, são (a maioria 
deles) respeitados e populares: lideram a zoeira, são mais velhos, reconhecidos pelos colegas como mais experientes e vividos, despojados e corajosos.

Essa constatação (tardia na minha relação com esse projeto, o que faz pensar sobre perspectivas de observação) me lembra de uma clássica afirmação de Mauss (2010:243) sobre a formação de um meio com sua própria moral em uma sociologia da infância: "O meio infantil é sempre, sobretudo quando é livre, e não o fruto de uma educação, mas sim de uma educação das crianças pelas próprias crianças, uma forma de compreender esses fenômenos muito vastos das gerações”. Há nisso a pista de uma forma de se relacionar com a escola, de se relacionar com os outros, que corre por fora dos ordenamentos e ritmos institucionais; ou melhor, participa deles, já que jovens relativamente mais velhos são agrupados a partir de seu estágio escolar.

Ainda que seguidamente a instituição de ensino tente elencar seus próprios exemplos ou, eventualmente, situe alguns desses jovens relativamente mais velhos das turmas enquanto exemplo negativo, demarcados enquanto repetentes, tal como aparece na citação do ressentimento daquele aluno, há evidentemente uma outra moral que não se restringe às qualificações escolares. Em meio a isso, aparece algo que percebo como uma espécie de despojamento na expressão dessa dissidência, que atravessa tanto a condição de estudante quanto esses fenômenos muito vastos que podemos agrupar nas noções de juventude ou adolescência e aí produz ressonâncias.

Esse despojamento é marcante nessas presenças na escola e na manutenção de certo distanciamento dela, tanto nas investidas por engajar esses discentes nas proposições, nas "chances" e "oportunidades" que são dadas quanto na coerência entre eles com uma identidade que passa muito pela reiteração dessa posição. Tal desprendimento se insinua como um investimento na construção dessa dissidência, na dimensão de uma elaboração moral dos estudantes. Uma cena comum sobre a banalidade disso e sua conexão com a dinâmica entre moral e reputação aparece em um fragmento do meu diário de campo:

Uma aula que começa 10h30, depois do recreio. $10 \mathrm{~h} 33$ entra o primeiro aluno na sala, completamente absorvido na tela do celular. Já no meio da sala, olha em volta, constata que foi o primeiro a chegar, deixa escapar uma exclamação, absorto no susto da constatação de ter sido o primeiro a entrar: “Não, não!”. Vira as costas e sai rápido, olhando para baixo, ignorando um olhar incrédulo do professor. Retorna quase quinze minutos depois, quando outros já entraram, em grupos.

A perene zoeira escolar passa muito por certo policiamento de identidades, eventualmente da negação de certas identidades mais incluídas nos ordenamentos escolares; como ser ou não ser um dos primeiros a entrar em uma sala de aula. Da parte dos professores, durante as variadas tentativas de administrar uma dinâmica em classe durante essas investidas desestabilizantes da zoeira, há um esforço constante de enfatizar outro perfil, mais atravessado e envolvido nesses ordenamentos escolares. Trata-se da desvalorização da zoeira (e do personagem do zoeiro) como infantil, relacionada(o) a atrasos na progressão das aulas. Curiosamente, Schneider (2003) destaca a caracterização do comportamento dos estudantes em "maduros" e "imaturos" como o primeiro exemplo de diferenciação na carreira escolástica das crianças, que demonstraria a alta predisposição do sistema para classificar e categorizar as condutas, antecipando desvios. 
Pereira (2010) discute a centralidade e certa ambiguidade da zoeira no cotidiano escolar em sua etnografia, na qual destaca a dificuldade em discernir, na experiência de campo, as diferenças sutis entre insulto, brincadeira, conflito ou ofensa. Ao se debruçar sobre essas socialidades estudantis, o autor recupera as relações de dádiva no clássico de Marcel Mauss, para identificar uma correspondência na vivência escolar da reciprocidade em torno da chacota (dar, receber, retribuir). Essa dinâmica estaria diretamente envolvida nas ambiguidades da jocosidade:

Assim, como ressalta Mauss (2001), ao refletir sobre os dois sentidos que a palavra gift adquiriu na língua inglesa e na língua alemã: presente em um e veneno no outro, o presente dado nas relações de dádiva carregaria consigo a incerteza sobre sua natureza boa ou má; da mesma forma, as gozações também ostentariam uma indefinição sobre seu caráter. (Pereira 2010:160)

A partir dessas noções, o autor procura, pela chave das sociabilidades jocosas, interpretar a complexidade das relações estabelecidas no ambiente escolar no desenrolar das ações. Explorando a chacota como dádiva, bem como os diferentes jogos e tipos de respostas entre as distintas assimetrias que compõem o cenário, ele destaca essa chave como entrada para essa difícil tarefa de apreender os limites e a variabilidade dessas ações e relações.

Em consonância com o que Pereira observou e, para além desses esforços cotidianos de valorização docente de um outro perfil em oposição ao zoeiro, percebo também certa ambiguidade em torno da zoeira, principalmente pela dinâmica de uma elaboração moral dos estudantes, no que tange à reputação deles dentro da escola.

\section{Considerações finais}

Tendo percorrido e comentado algumas clivagens e projeções que apareceram em torno do CAIS, como em torno das trocas e dos agrupamentos envolvidos, acho pertinente encerrar este artigo com algumas inquietações e reticências que atravessaram essa experiência de um modo mais geral. Já abordei a questão da aceleração e da negação ao longo destas páginas, enquanto algo que se insinuou ao longo deste trabalho. Diante da incumbência mais prática do planejamento e desenvolvimento das aulas, questionou-se muito a desmotivação ou resistência desses alunos.

Alguns professores se inquietaram especialmente com isso, inconformados principalmente diante das dificuldades em desenvolver um trabalho com esses estudantes em sala de aula. Dessa maneira, sugeriram propostas, logo no início do ano letivo, para fazê-los falar, pensando sobre o que essa insistência em não se engajar teria a dizer efetivamente, para além do que se manifestava na zoeira, gesto ou postura. Percebi essa inquietação muito no sentido de "o que vocês têm a dizer sobre a escola daí, dessa negação, dessa posição de exterioridade”.

Essa inquietude estava atrelada a uma expectativa de elaboração dessa negação da escola, para uma posterior problematização da própria prática docente. Digo isso de uma forma geral, a partir das conversas que tive ou presenciei sobre essa questão entre os professores, mas, principalmente, desde duas entrevistas especialmente longas com dois dos docentes do CAIS, que promoveram diferentes iniciati- 
vas para fazer esses alunos falarem sobre suas perspectivas, sobre as próprias posições na escola, para talvez as traduzir em proposições e projetos de trabalho, a serem incorporados nas dinâmicas de suas aulas.

Diante disso, apareceu pouca coisa (no entendimento também desses professores) para além de conjugações de um desgaste nas relações, com a rotina escolar, com o uniforme. Resumidamente, foram iniciativas marcadas por frustração. E, em meio a isso, eventualmente apareciam as mesmas máximas relacionadas ao reconhecimento da importância da escola para o futuro de cada um, "para ser alguém", motivo alegado pelo qual não desistiam. Considero essas máximas reproduzidas por eles extremamente significativas, como já destaquei, em paralelo com uma projeção de fracasso escolar que pesava, enquanto processo de subjetivação.

Percebo que o mais potente, em meio a essas iniciativas e frustrações nesse projeto como um todo, foi uma paradoxal desaceleração, haja vista tratar-se de uma iniciativa atravessada pela ideia de aceleração. Notei isso na imaginação da escola enquanto espaço comum; nas discussões de proposições institucionais de forma generalista acerca dos encadeamentos necessários; dos métodos de avaliação meritocráticos; da produção e formação do estudante idealizado, com todo o impacto e a hesitação que essa imagem transporta para a produção de diferenças dentro de uma escola pública tradicional, tida como de excelência, expressos, por exemplo, no risco de produzir mais distâncias e estigmas.

O projeto foi todo permeado, portanto, por urgências e hesitações, por desacelerações, no desafio de produzir algum engajamento, de conquistar a passagem pelo Ensino Fundamental (e o que foi esse "fundamental"? O que se impõe como "fundamental"?), de preparar para o que vem depois (e o que vem depois?), de procurar o mais importante em meio a tudo isso e em cada história.

Essa hesitação remete-me muito a uma ideia de suspensão e lentidão no pensamento de Isabelle Stengers. É algo de uma provocação e profundidade difíceis de serem abreviadas, mas que, concentradas em sua clássica "proposição cosmopolítica", estabelecem um operador (cosmopolítico $\left.{ }^{4}\right)$ de "colocação em igualdade" sob a condição de dissociá-la radicalmente de uma "colocação em equivalência". Isso implicaria uma medida comum e a intercambialidade de posições. Dessa colocação em igualdade não se desdobra naturalmente um "e portanto...", pelo contrário, põe em suspensão os "e portanto...":

O cosmos, tal qual ele figura nesse termo, cosmopolítico, designa o desconhecido que constitui esses mundos múltiplos, divergentes, articulações das quais eles poderiam se tornar capazes, contra a tentação de uma paz que se pretenderia final, ecumênica, no sentido de que uma transcendência teria o poder de requerer daquele que é divergente que se reconheça como uma expressão apenas particular do que constitui o ponto de convergência de todos. Não existe, enquanto tal, um representante, o idiota nada exige, não autoriza nenhum "e portanto.... E a sua questão se dirige, então, primeiramente àqueles que são os mestres do "e portanto...", a nós que, com grandes doses de "e portanto", bem poderíamos, com toda nossa boa vontade, nos tornar os representantes de problemas que, queiramos ou não, se impõem a todos. (Stengers 2018:447).

4 Esse operador tem afinidade com o personagem conceitual que Deleuze fez existir com força, o idiota de Dostoiévski, que é referido na passagem de Stengers que cito na sequência do corpo do texto. Sobre ele: "O idiota de Deleuze, que ele tomou de empréstimo de Dostoiévski para dele fazer uma personagem conceitual, é aquele que sempre desacelera os outros, aquele que resiste à maneira como a situação é apresentada, cujas urgências mobilizam o pensamento ou a ação. E resiste não porque a apresentação seja falsa, não porque as urgências sejam mentirosas, mas porque 'há algo de mais importante.' Que não lhe perguntemos o quê. O idiota não responderá, ele não discutirá. O idiota faz presença, ou, como diria Whitehead, ele coloca um interstício” (Stengers 2018:444). 
A questão nessa "proposição cosmopolítica" é fazer pensar em uma desaceleração dos raciocínios habituais, criadora da ocasião de uma outra sensibilidade no que diz respeito a problemas e situações que nos mobilizam. O interessante aqui, dessa proposição, é fazer ressoar as lacunas que se colocam diante de problemas como a multirrepetência, para além da forma como é respondida institucionalmente ou do que efetivamente é dito ou não dito pelos alunos, passível de ser representado em outros níveis. Essa proposição, segundo Stengers, apenas adquire sentido nas situações concretas, nas quais trabalham os praticantes, e não nas teorias generalizantes; é uma inquietação na prática. Essa igualdade de que a autora fala, que não desdobraria nenhum "e portanto", seria justamente o que colocaria esse habitual em suspensão, nada tendo a ver com um programa de trabalho, porém, muito mais com a passagem de um pavor que faria balbuciar as seguranças.

Ela fala então de uma "colocação em inquietude" das vozes políticas que habitam esses problemas, diante do sentimento de que não definem exatamente aquilo que colocam em discussão. Essa arena seria povoada pela sombra do que não tem ou não quer ter voz política, o que a boa vontade (política, institucional) poderia tão facilmente obliterar, "no momento em que uma resposta não puder ser articulada à exigência 'exprima-se, explicite suas objeções, suas proposições, sua relação com o mundo comum que nós construímos"” (Stengers 2018: 447).

Acredito que nessa intrincada proposição está uma pista sobre a dificuldade de positivação dessas presenças estudantis, para além da negatividade; de uma negação da regularidade escolar, desse “mundo comum que nós construímos”. Essa regularidade escolar está envolvida em concepções sobre juventude e sobre se produzir enquanto um estudante, atrelada a comportamentos esperados. Em uma concatenação de momentos, passagens e ritmos: a idade apropriada; a atenção e o comportamento esperados e investidos; e, finalmente, a produção do estudante aspirado. O desafio seria fazer hesitar esses registros, paradoxalmente quando se trabalha para adequar a partir deles.

Em torno do CAIS, foi possível entrever, etnograficamente, alguns deslocamentos e desacomodações que, constantemente, materializavam-se na dimensão da (in)disciplina. Diante disso, dessa paradoxal desaceleração em um projeto como esse, nas diferentes imaginações que surgiram em torno da instituição de ensino enquanto espaço comum, a questão esteve e está em (re)pensar esse universo na presença de questões insistentes (embora não formuladas e, de certa forma, não explicadas) que esses alunos fazem existir, as quais pluralizam as perspectivas sobre o que é concebido, habitualmente, em torno das ideias de fracasso escolar.

Mario Borba é Doutor em Antropologia pela Universidade Federal Fluminense (UFF) e Pesquisador Associado ao Laboratório de Etnografias e Interfaces do Conbecimento da Universidade Federal do Rio de Janeiro (UFRJ). Foi bolsista CAPES. 


\section{REFERÊNCIAS BIBLIOGRÁFICAS}

Angelucci, Carla, Jaqueline Kalmus, Renata Paparelli, Maria Helena Patto. 2004. "O estado da arte da pesquisa sobre fracasso escolar (1991-2002): um estudo introdutório”. Educação e Pesquisa 30(1): 51-72. doi: https://doi.org/10.1590/S1517-97022004000100004

Ariès, Philippe. 1978. História social da criança e da familia. Rio de Janeiro: Zahar.

Bahia, Norinês. 2009. "Formação de professores em serviço: fragilidades e descompassos no enfrentamento do fracasso escolar". Educação e Pesquisa 35(2): 317-329. doi: http://dx.doi.org/10.1590/ S1517-97022009000200007

Borba, Mario. 2019. Entre produtividades, compassos e dispersões: mobilizações de atenção e cuidado no cotidiano escolar. Tese de Doutorado. Programa de Pós-Graduação em Antropologia, Universidade Federal Fluminense.

Borba, Mario e Rogerio Azize. 2020. "Engajamentos, aprendizados, sistematizações: reflexões sobre um projeto de aceleração". Revista Contemporânea de Educação 15(32): 66-82. doi: http://dx.doi. org/10.20500/rce.v15i32.33603

Bossa, Nádia. 2008. Fracasso escolar: um olhar psicopedagógico. São Paulo: Artmed.

Bourdieu, Pierre. 1983. Questões de sociologia. Rio de Janeiro: Marco Zero.

Bourdieu, Pierre (coord). 2003. A miséria do mundo. Petrópolis: Vozes.

Carvalho, Marília. P. 2003. "Sucesso e fracasso escolar: uma questão de gênero". Educação e Pesquisa 29(1): 185-93. doi: https://doi.org/10.1590/\$1517-97022003000100013

Cury, Carlos. 1988. Ideologia e educação brasileira: católicos e liberais. São Paulo: Cortez.

Deleuze, Gilles. 2010. Conversações. São Paulo: Ed. 34.

Fischer, Rosa M. B. 1996. Adolescência em discurso: mídia e produção de subjetividade. Tese de Doutorado. Programa de Pós-Graduação em Educação, Universidade Federal do Rio Grande do Sul.

Fonseca, Maria. 2001. Discurso, memória e inclusão: reminiscências da matemática escolar de alunos adultos do ensino fundamental. Tese de Doutorado. Programa de Pós-Graduação em Educação, Universidade Estadual de Campinas.

Foucault, Michel. 2012. História da sexualidade 1: a vontade de saber. Rio de Janeiro: Graal. 
Franch, Mónica. 2008. Tempos, contratempos e passatempos: um estudo sobre práticas e sentidos do tempo entre jovens de grupos populares do Grande Recife. Tese de Doutorado. Programa de Pós-Graduação em Sociologia e Antropologia, Universidade Federal do Rio de Janeiro.

Franch, Mónica. 2016. Tardes ao léu: uma etnografia sobre o tempo livre entre jovens de periferia do Recife. João Pessoa: Editora da UFPB.

Franch, Mónica. 2018. "De tempos em tempos: reflexões sobre a categoria de tempo nos estudos sobre juventudes”. Revista TOMO 32: 99-128. doi: 10.21669/tomo.v0i32.8838

Goldman, Marcio. 2016. Mais alguma antropologia. São Paulo: Ponteio.

Guedes, Simoni. 1997. Jogo de corpo: um estudo da construção social de trabalhadores. Niterói: EDUFF.

Gusmão, Neusa. 2014. “Trajetória, percalços e conquistas na antropologia da educação no Brasil”. Pp 13-24 in Abordagens etnográficas sobre educação: adentrando os muros das escolas, org. S. L. Guedes \& T. Cipiniuk. Rio de Janeiro: Alternativa.

Lima, Alef. 2018. "Onde há uma vontade há um caminho": uma etnografia da escolarização tardia na EJA do Colégio Aplicação/UFRGS. Dissertação de Mestrado. Programa de Pós-Graduação em Antropologia Social, Universidade Federal do Rio Grande do Sul.

Mauss, Marcel. 2010. “Três observações sobre a sociologia da infância”. Pró-posições 21(3): 237-244. doi: https://doi.org/10.1590/S0103-73072010000300014

Patto, Maria Helena. 2015. A produção do fracasso escolar: histórias de submissão e rebeldia. São Paulo: Intermeios.

Pereira, Alexandre. 2010. "A maior zoeira”: experiências juvenis na periferia de São Paulo. Tese de Doutorado. Programa de Pós-Graduação em Antropologia Social, Universidade de São Paulo.

Santos, Geovânia. 2003. "Educação ainda que tardia: a exclusão da escola e a reinserção de adultos das camadas populares em um programa de EJA”. Revista Brasileira de Educação 24:107-125. doi: https://doi.org/10.1590/S1413-24782003000300009

Schneider, Dorith. 2003. “Alunos Excepcionais': um estudo de caso de desvio”. Pp 52-81 in Desvio e Divergência: uma critica da patologia social, org. G. Velho. Rio de Janeiro: Zahar.

Silva, Jailson S. 2011. "Por que uns e não outros?": caminhada de jovens pobres para a universidade. Rio de Janeiro: 7 Letras.

Stengers, Isabelle. 2018. "A proposição cosmopolítica”. Revista do Instituto de Estudos Brasileiros 69: 442-464. doi: https://doi.org/10.11606/issn.2316-901X.v0i69p442-464 
Willis, Paul. 1991. Aprendendo a ser trabalhador. escola, resistência e reprodução social. Porto Alegre: Artes Médicas.

Zago, Nadir. 2000. "Quando os dados contrariam as previsões estatísticas: os casos de êxito escolar nas camadas socialmente desfavorecidas”. Paidéia 10(18): 70-80. doi: https://doi.org/10.1590/ S0103-863X2000000100007 


\title{
PROJEÇÕES DE ATRASOS E HESITAÇÕES: PERSPECTIVAS EM TORNO DE UM PROJETO DE ACELERAÇÃo EM UMA ESCOLA PÚBLICA DO RIO DE JANEIRO (RJ)
}

Resumo: Neste artigo, abordo a experiência de um projeto de adaptação idade-série ou de aceleração, relativo ao segundo ciclo do Ensino Fundamental (do sexto ao nono ano), a partir de uma etnografia que realizei em uma escola pública do Rio de Janeiro (RJ). Percorro diferentes perspectivas sobre a situação e os percursos dos jovens que compuseram suas duas turmas, em diálogo com os agrupamentos e trocas que esse projeto promoveu. Exploro projeções sobre atraso e aceleração na aprendizagem, do ponto de vista tanto de professores, quanto dos estudantes envolvidos. Diante de uma salutar hesitação que insiste entre perguntas e respostas que o fenômeno da multirrepetência nos coloca, destaco uma paradoxal desaceleração que essa experiência operou.

Palavras-chave: Escolarização; Projeto de aceleração; Repetência; Fracasso escolar.

\section{PROJECTIONS OF DELAYS AND HESITATIONS: PERSPECTIVES AROUND AN ACCELERATION PROJECT IN A PUBLIC SCHOOL IN THE CITY OF RIO DE JANEIRO, BRAZIL}

\begin{abstract}
In this article, I approach the experience of an age-grade adaptation project or accelerated learning program, related to the second cycle of Elementary Education (from the sixth to the ninth year), based on an ethnography that I carried out in a public school in the city of Rio de Janeiro, Brazil. The article goes through different perspectives on the situation and the paths of the young people who made up the two project classes, in dialogue with the groups and exchanges that it promoted. I explore projections about delay and acceleration in learning, from teachers' and students' points of view. Faced with a salutary hesitation that insists between questions and answers that the phenomenon of school failure poses, the discussion highlights a paradoxical deceleration that this experience operated.
\end{abstract}

Keywords: Schooling; Acceleration project; School failure.

RECEBIDO: $30 / 04 / 2020$

APROVADO : $05 / 01 / 2021$ 